\title{
A congruência de valores e o stress ocupacional em guardas prisionais: Congruência de valores e stress ocupacional
}

\author{
Ana Catarina Moreira Leal ${ }^{1} \&$ Filomena Jordão ${ }^{2}$ \\ ${ }^{1}$ Faculdade de Psicologia e Ciências da Educação da Universidade do Porto \\ ${ }^{2}$ Departamento de Psicologia, Faculdade de Psicologia e Ciências da Educação da Universidade do Porto
}

\begin{abstract}
Resumo: Pressupondo que as organizações e os guardas prisionais detêm um conjunto de valores sobre como reduzir o crime, correspondente a uma abordagem reabilitativa e/ou punitiva, que podem, ou não, coincidir, pretende-se explorar com base no Modelo Person-Environment fit, a relação entre a congruência de valores e o stress ocupacional vivenciado por guardas prisionais portugueses. Os dados foram recolhidos através da análise documental e entrevista semiestruturada individual realizada a oito guardas prisionais. Conclui-se que os valores, punir e ressocializar, são independentes e interagem entre si e que a congruência de valores, que se manifesta através de três conceitos independentes, fit, misfit e conflito de valores, é um elemento crítico da vida nas prisões. Constata-se, de facto, a existência de dois tipos distintos de conflito e que a ausência de fit não é indicador de conflito. Estes resultados são interpretados considerando-se as implicações teóricas e práticas para as organizações e guardas prisionais.
\end{abstract}

Palavras-chave: Stress ocupacional; Person-Environment fit; Congruência de valores; Guardas prisionais.

The congruence of values and occupational stress in prison guards: Congruence of values and occupational stress: Assuming that organizations and prison guards possess a set of values about the best way to reduce crime - corresponding to a rehabilitative and/or punitive approach - which can either coincide or not, is intended to exploit, based on the P-E Fit Model, the relationship between congruence of values and occupational stress experienced by Portuguese prison guards. The data were collected through documental analysis and individual semi structured interviews performed to eight prison guards. It is concluded that the values punish and resocialize are independent and interact with each other and that the congruence of values, which manifests itself through three independent concepts (fit, misfit and conflict of values) is a critical element of prisons. In fact, we found two distinct types of conflict and the absence of fit is not an indicator of conflict. These results are interpreted considering the theoretical and practical implications for organizations and prison guards.

Keywords: Occupational Stress; Person-Environment fit; Congruence of Values; Prison Guards.

O facto de o mundo do trabalho ser cada vez mais competitivo, leva a que os trabalhadores tenham a difícil tarefa de responderem de forma adaptativa às exigências constantes que o ambiente lhes coloca. Quando esta adaptação não é bem-sucedida o trabalhador experiencia stress (Isenhardt et al., 2019). Segundo a teoria do P-E fit, o stress resulta do desajustamento entre as características da pessoa e do ambiente (Edwards \& Cable, 2009). Sendo que o ambiente de trabalho é, em grande parte, determinado pelos valores organizacionais, é importante estudar a relação entre a congruência de valores e o stress ocupacional, já que um dos aspetos fundamentais e duradouros, tanto das organizações como das pessoas, são os seus valores (Lambert et al., 2019).

Segundo Arruda (2013), é particularmente relevante investigar a congruência de valores em funções da área das forças de segurança pública, como é o caso da função de guarda prisional.

As instituições prisionais enquadram-se no sistema penal e foram durante muitos séculos tidas como espaços repressivos, de castigo, em que a reclusão não era considerada uma medida de execução penal (Pereira, 2011). Contudo, no século XX, a reclusão passa a ser reconhecida como uma forma de prevenção, corresponsabilização e ressocialização (Cardoso, 2014), emergindo um modelo prisional que considera o potencial ressocializador da prisão. Neste sentido, o sistema prisional português apresenta atualmente uma dupla orientação: punir e ressocializar e o guarda prisional passa a ter um papel simultaneamente, "violento e coercivo e (...) humanizador e direcionado para a reinserção social" (Pereira, 2011, p.21). Ora estas duas orientações são encaradas, pela maioria dos autores (e.g., Isenhardt et al., 2019), como sendo

${ }_{1}^{1}$ Morada para correspondência: Ana Catarina Moreira Leal, Rua do Capelão, n $68,1^{\circ}$ esquerdo, 4580-650, Duas Igrejas, Paredes. E-mail: analeal22993@gmail.com 
contraditórias, incompatíveis e mutuamente exclusivas configurando um modelo baseado na competição de valores. Este modelo baseia-se na necessidade do ser humano em procurar um sentido de coerência e consistência entre as cognições que são essenciais para a sua autoidentidade, uma vez que, de acordo com a teoria da dissonância cognitiva (Festinger, 1957), as pessoas não conseguem viver com a tensão que deriva do conflito de valores, gerador de stress ocupacional.

\section{Person-Environment (P-E) Fit}

As teorias de $P$-E fit assumem que é necessário conhecer a interação que ocorre entre as características da pessoa e do ambiente de modo a compreender realmente as causas de stress (Cooper \& Marshall, 1976). Neste âmbito, French e colaboradores (1982) propõem o P-E fit model cuja premissa básica é a de que quando as características das pessoas e do ambiente de trabalho são similares, surgem consequências positivas para os indivíduos, nomeadamente menores níveis de stress (Edwards \& Cable, 2009). Segundo esta teoria, um misfit entre as características do indivíduo e as do ambiente pode causar problemas, sendo que quanto maior for a discrepância entre a pessoa e o ambiente maior será a tensão fisiológica, psicológica e comportamental experienciada pelo indivíduo (Lambert et al., 2019).

Este modelo considera dois tipos de fit entre a pessoa e o ambiente: o $P$-E fit objetivo e o $P$ - $E$ fit subjetivo (Edwards \& Cable, 2009). O P-E fit objetivo descreve a congruência entre as características reais da pessoa e as do meio objetivos, e o $P$-E fit subjetivo descreve o fit entre a pessoa e o ambiente subjetivos. No entanto, este modelo considera que o stress deriva, principalmente, do misfit subjetivo entre a pessoa e o meio (Edwards \& Cable, 2009), uma vez que as perceções dos indivíduos são as principais responsáveis pelas suas atitudes e comportamentos (Schiff \& Leip, 2019). Deste modo, este modelo considera que o misfit subjetivo entre a pessoa e o meio pode levar a respostas físicas, psicológicas e comportamentais (Edwards \& Cable, 2009), que ocorrem "como uma manifestação da tensão nos ambientes organizacionais, produtos da interação entre fatores ambientais, condições de trabalho, perceções e comportamentos do indivíduo no plano da cultura das organizações" (Ramos e Jordão, 2013, p. 400).

\section{Person-Organization Fit}

A cultura organizacional é o conjunto de valores nucleares, normas de comportamento, artefactos e padrões de comportamento que governam a forma como as pessoas interagem numa organização e o modo como se empenham no trabalho e na organização (Schein, 2010). Este conjunto de premissas implícitas, compartilhadas e assumidas por um grupo, modela os seus comportamentos e permite a formação de uma identidade corporativa (Schein, 2010; Ramos \& Jordão, 2013) que é particularmente evidente em culturas organizacionais de cariz militar, como é o caso dos estabelecimentos prisionais. Estes contextos são marcados por uma forte imposição de comportamentos, valores e regras, a qual é feita logo desde o início do percurso profissional dos guardas prisionais na sua formação e integração em contexto prisional (Roseira, 2017).

Os valores são o elemento que, em grande medida, afeta a cultura da organização, sendo perpetuados através do processo de socialização (Schein, 2010) através do qual são transmitidos aos novos membros da organização, não só, um conjunto de valores formais e explícitos, como também, um conjunto de valores informais e implícitos, baseado no companheirismo dos membros da organização (Schein, 2010). Um aspeto fundamental e duradouro, tanto das organizações como das pessoas, são os seus valores (Ramos \& Jordão, 2013), os quais constituem princípios ou crenças duradouras sobre comportamentos sociais ou estados de existência - que transcendem situações específicas -, que guiam a seleção ou avaliação de comportamentos ou eventos e que são ordenados hierarquicamente a partir da sua importância relativa (Schein, 2010). A nível organizacional identificam-se valores individuais e valores organizacionais (Ramos \& Jordão, 2013). Enquanto que os valores individuais têm como função orientar as atitudes e os comportamentos das pessoas, os valores organizacionais orientam a vida da organização e os comportamentos dos seus membros (Edwards \& Cable, 2009).

A relação que se estabelece entre os valores pessoais e os valores organizacionais terá um impacto significativo tanto nos trabalhadores como na própria organização (Ramos \& Jordão, 2013), sendo que o alinhamento entre estes dois tipos de valores conduz ao conceito de Person-Organization (P-O) fit, que reflete o grau de compatibilidade entre o trabalhador e a organização (Ramos \& Jordão, 2013). Embora este conceito possa ser definido de diversas formas, a literatura evidencia que a maioria das investigações tende a estudar o $P$-O fit a partir da congruência de valores. Esta concetualização encontra-se, normalmente, associada ao conceito de fit subjetivo, que traduz as perceções que os trabalhadores têm sobre o facto de os seus valores irem ao encontro dos valores organizacionais (Edwards \& Cable, 2009). No entanto, segundo o modelo de congruência de valores proposto por Liedtka (1989), a congruência de valores é um conceito muito mais amplo que o conceito de fit, uma vez que aquela pode manifestar-se através do fit, 
misfit e conflito de valores (Ramos \& Jordão, 2013). Neste trabalho iremos abordar a congruência de valores segundo esta perspetiva.

\section{Relação entre Stress Ocupacional e Congruência de valores em Guardas Prisionais}

Vários estudos têm indicado que o fit de valores terá um impacto fundamentalmente positivo tanto para a organização como para os próprios trabalhadores (Butler et al., 2019; Lambert et al., 2019), uma vez que quando os indivíduos possuem valores que vão ao encontro dos valores da sua organização estão mais satisfeitos com o seu trabalho, identificam-se e vinculam-se à organização, evidenciam um maior comprometimento organizacional e demonstram menores níveis de stress e sintomas psicossomáticos, maior bem-estar emocional e satisfação a nível familiar (Edwards \& Cable, 2009; Trounson et al., 2019 ).

Uma vez que o que o indivíduo procura no seu trabalho é, em grande medida, determinado pelas suas necessidades e valores (Butler et al., 2019; Ramos \& Jordão, 2013), quando existe uma incongruência ou incompatibilidade entre o que o trabalhador espera alcançar no seu trabalho e aquilo que os valores da organização o permite, realmente, obter, é muito provável que o trabalhador experiencie stress (Ramos \& Jordão, 2013). Neste sentido, o stress tende a atingir níveis mais severos quando os indivíduos acreditam que foram obrigados a comprometer os seus valores individuais de modo a responderem às exigências organizacionais - conflito de valores (Trounson et al., 2019). Por outro lado, as pessoas experienciam bemestar quando enaltecem os mesmos valores que prevalecem no seu ambiente de trabalho (Isenhard et al., 2019).

Em Portugal, a congruência de valores tem sido um tema negligenciado na investigação (Ramos \& Jordão, 2013), uma vez que os estudos realizados tendem apenas a focar-se no $P$ - $O$ fit. No entanto, Ramos e Jordão (2013) desenvolveram dois estudos que demonstraram que o fit e o conflito entre a pessoa e a organização devem ser tratados como variáveis independentes, sendo que o conflito de valores é a única variável que está associada a experiências negativas na organização, como o stress ocupacional. A partir dos estudos de caso desenvolvidos por estas autoras numa empresa portuguesa, concluiu-se que o stress ocupacional está correlacionado positivamente com o conflito de valores e negativamente com o P-O fit. De facto, os trabalhadores evidenciavam níveis de stress significativos quando percecionavam que os seus valores pessoais eram incompatíveis com os valores da sua organização (Ramos \& Jordão, 2013).

De um modo geral, as investigações realizadas no domínio dos estabelecimentos prisionais, corroboram, direta ou indiretamente, a teoria do $P$-E fit. Todavia, a maioria dos estudos tende a focar-se no Person-Job (P-J) fit, havendo poucos estudos que explorem a relação existente entre o $P$-O fit e o stress ocupacional (Butler et al., 2019; Lambert et al., 2019).

Lambert et al. (2019) demonstraram que variáveis como conflito e/ou ambiguidade de papéis estão relacionadas com níveis mais elevados de stress ocupacional. Os autores sugerem que aspetos como a justiça organizacional, comunicação instrumental, e a participação no processo de tomada de decisão, levam a que os trabalhadores prisionais reportem menores níveis de stress ocupacional (Lambert et al., 2019). Este estudo conclui que as organizações e os trabalhadores prisionais têm melhores resultados, quando os trabalhadores percecionam que as suas necessidades são satisfeitas. Quando tal não acontece, segundo a teoria da Atração-Seleção-Atrito (Schneider, 1987), os trabalhadores tendem a abandonar a organização (Butler et al., 2019)

Trounson et al. (2017) desenvolveram um estudo, junto dos colaboradores de um estabelecimento prisional de alta segurança nos EUA, cujos valores organizacionais estavam, maioritariamente, orientados para a ressocialização dos reclusos. Concluiu-se que os trabalhadores que detinham uma orientação predominantemente punitiva - P-O misfit - evidenciavam níveis significativamente mais elevados de stress e conflito de papel e, significativamente, mais baixos de satisfação com a vida, comprometimento moral e perceção de justiça organizacional, quando comparados com os trabalhadores que detinham uma orientação predominantemente reabilitativa - $P$-O fit.

Em Portugal são escassos os estudos sobre os guardas prisionais (Costa et al., 2017). Destaca-se o trabalho de Gonçalves e Vieira (2005), no qual os autores defendem a formação dos guardas prisionais como recurso auxiliador e facilitador em situações de dificuldades complexas. Já o estudo de Silva e Gonçalves (1999) salienta que as características ambientais do local de trabalho e relacionamento com os reclusos contribuem para a instabilidade emocional dos guardas prisionais, evidenciando o que Cunha (1996) já havia salientado: que os riscos de saúde a que os guardas prisionais poderão estar sujeitos colocam em causa o seu bem-estar pessoal e o sucesso da sua organização. Coelho (2008) refere que atualmente se atribui importância ao papel dos guardas prisionais, pois eles garantem a segurança dos reclusos, dos funcionários, e da sociedade, já que uma das suas funções, dentro dos parâmetros legais, é procurar a ressocialização do recluso, promover a sua segurança, orientação e disciplina, independentemente do crime (Pereira, 2011). Neste sentido, Cardoso (2014) realça a contraditoriedade existente em situações adversas repetitivas e desafiantes que tal como podem originar oportunidade para 
desenvolver estratégias adequadas, podem, por outro lado, potenciar um mal-estar contínuo que vulnerabiliza os sujeitos influenciando a saúde e o desempenho organizacional dos mesmos. 0 autor frisa assim a importância de aprofundar o estudo do stress ocupacional no Corpo da Guarda Prisional, uma vez que estes profissionais estão sujeitos a uma série de potenciais stressores que não estão presentes no dia a dia das restantes forças de segurança.

Já anteriormente alguns autores tinham salientado esta necessidade. Santos (2010), por exemplo, defendeu um maior interesse e preocupação pelos fatores de risco a que os guardas prisionais estão sujeitos. Gonçalves e Vieira (2005) chamaram a atenção para a importância de refletir sobre a profissão do guarda prisional enquanto profissão exigente, stressante, dura e desgastante que exige e depende de uma boa gestão e equilíbrio emocional. Considerando que a atividade ocupacional dos profissionais de segurança, nomeadamente a de guarda prisional, é das mais stressantes do mundo (Gonçalo et al., 2010), Afonso e Gomes (2009) destacam ainda a importância de alargar a investigação da vivência do stress ocupacional a outras forças policiais, nomeadamente à de guarda prisional, que, segundo os mesmos, é a força de segurança mais negligenciada ao nível da investigação nacional.

Verifica-se, assim, que já foram realizados esforços para estudar o burnout e stress nesta população que além de assumir funções de vigilância e controlo, assume um papel proeminente na ressocialização dos internos e de apaziguamento da vida na prisão (Arruda, 2013; Gonçalo et al., 2010; Moreira, 2016; Gonçalves e Vieira, 2005). Estes estudos apontam os fatores que mais contribuem para o stresse ocupacional no trabalho prisional: problemas de relacionamento (com colegas, supervisores ou reclusos); sobrecarga de trabalho; baixo status social da profissão e a falta de apoio social. Também foram citados o "conflito de papéis" (papel punitivo vs. papel reabilitativo) e as poucas oportunidades de promoção, que ao interagirem com fatores individuais como personalidade e conflitos familiares, podem gerar problemas na saúde mental e física dos guardas prisionais. Todavia, nos estudos que consideram o "conflito de papéis" um fator potenciador de stress nesta profissão, os investigadores consideram que ainda é necessário desenvolver mais estudos que identifiquem os múltiplos fatores a ele associados (Costa et al., 2017; Gonçalo et al., 2010; Moreira, 2016).

A revisão bibliográfica permite destacar a transversalidade da opinião de distintos autores em relação ao impacto das características individuais (género, etnia, idade, nível educacional, experiências na prisão) nos níveis de stresse ocupacional destes profissionais. A variável "satisfação no trabalho" está intimamente ligada ao stress sendo, até à data, a mais forte preditora sobre quaisquer outras variáveis (Costa et al., 2017). No entanto, segundo Moreira (2016), ainda é necessário compreender melhor quais são os fatores que realmente condicionam a perceção de "satisfação no trabalho" e qual é o impacto que a presença, ou ausência, desses fatores têm na vivência do stress ocupacional.

Foram identificados alguns estudos que relacionam a orientação dos guardas prisionais relativamente à melhor forma de reduzir o crime e os níveis de stress experienciados por estes últimos. Estes estudos indicam que os guardas prisionais que detêm, maioritariamente, valores reabilitativos tendem a demonstrar menores níveis de stress ocupacional do que aqueles que privilegiam valores punitivos (Cardoso, 2014). Uma vez que os guardas prisionais detêm um conjunto de valores sobre a melhor forma de reduzir o crime - através de uma abordagem reabilitativa ou uma abordagem punitiva (Lambert et al., 2019) - que pode coincidir, ou não, com os valores punitivos e/ou reabilitativos, defendidos explícita ou implicitamente pelo seu estabelecimento prisional, justifica-se explorar a relação entre a congruência de valores e o stress ocupacional vivenciado por estes profissionais.

Assim, considerando a perspetiva dos guardas prisionais, pretende-se responder às seguintes questões de investigação: QI.1) Quais são os valores pessoais e organizacionais que são reconhecidos pelos guardas prisionais?; QI.2) Em que medida é percecionada congruência de valores pelos guardas prisionais?; QI.2.1) Em que medida é percecionado P-O fit subjetivo pelos guardas prisionais?; QI.2.2) Em que medida os guardas prisionais percecionam conflito entre os seus valores individuais e os valores organizacionais que reconhecem?; QI.3) Qual a relação entre a congruência de valores e o stress vivenciado pelos guardas prisionais?; QI.3.1) Qual a relação entre o P-O fit subjetivo e o stress vivenciado pelos guardas prisionais? QI.3.2) Qual a relação entre o conflito de valores e o stress vivenciado pelos guardas prisionais?

\section{MÉTODO}

Considerando o exposto, optamos metodologicamente por uma abordagem qualitativa exploratória e descritiva (Sampieri et al., 2014; Yin, 2011) ao tema. Atendendo ainda a que as fronteiras entre o fenómeno em estudo e o contexto não estão claramente diferenciadas, adotou-se como desenho metodológico o estudo de caso, mais especificamente o estudo de caso simples (caso único) embutido - com várias unidades de análise (Yin, 2011). Neste sentido, a função de guarda prisional é o caso e as unidades de análise, os participantes no estudo. 


\section{Participantes}

Os participantes deste estudo são guardas prisionais que desempenham a sua função em estabelecimentos prisionais portugueses. A amostra é não probabilística, por conveniência, é por bola de neve (Yin, 2011), tendo sido estabelecido inicialmente o contacto com dois guardas prisionais através dos quais se acedeu aos restantes participantes do estudo. 0 tamanho da amostra foi definido após se ter atingido a saturação teórica dos dados (Patton, 2015).

Neste estudo colaboraram oito guardas prisionais (cf. Tabela 1) de estabelecimentos prisionais com diferentes níveis de segurança com idades compreendidas entre os 30 e os 57 anos $(M=39.7 ; D P=10.01)$, sendo a maioria do sexo feminino (62.5\%). Metade são casados, possui o 12. ano de escolaridade e trabalha, atualmente, num estabelecimento prisional com um nível de segurança alto. Os participantes têm entre 4 a 32 anos $(M=13.75 ; D P=10.69)$ de serviço e desempenham funções no atual estabelecimento prisional entre os 2 e os 21 anos $(M=10.5 ; D P=7.43)$.

Tabela 1. Caracterização dos participantes

\begin{tabular}{|c|c|c|c|c|c|c|c|}
\hline Participantes & Sexo & $\begin{array}{l}\text { Idade } \\
\text { (anos) }\end{array}$ & $\begin{array}{l}\text { Estado } \\
\text { Civil }\end{array}$ & $\begin{array}{l}\text { Nível de } \\
\text { Escolaridade }\end{array}$ & $\begin{array}{l}\text { Antiguidade } \\
\text { na função } \\
\text { (anos) }\end{array}$ & $\begin{array}{l}\text { Antiguidade } \\
\text { no EP atual } \\
\text { (anos) }\end{array}$ & $\begin{array}{l}\text { Nível de } \\
\text { segurança } \\
\text { do EP atual }\end{array}$ \\
\hline P01 & Feminino & 50 & Casado & 12. ${ }^{\circ}$ ano & 29 & 20 & Alto \\
\hline $\mathrm{P} 02$ & Feminino & 30 & Solteiro & 12. ${ }^{\circ}$ ano & 4,5 & 2 & Médio \\
\hline P03 & Masculino & 44 & Casado & Licenciatura & 19 & 18 & Alto \\
\hline P04 & Masculino & 57 & Casado & 9.. ano & 32 & 21 & Alto \\
\hline P05 & Feminino & 31 & Divorciado & Licenciatura & 5 & 3 & Médio \\
\hline P06 & Masculino & 30 & Solteiro & 12. ${ }^{\circ}$ ano & 7 & 7 & Alto \\
\hline P07 & Feminino & 36 & Casado & $12 .^{\circ}$ ano & 9,5 & 9 & Especial \\
\hline P08 & Feminino & 35 & Solteiro & Licenciatura & 4 & 4 & Médio \\
\hline
\end{tabular}

\section{Técnicas de Recolha de Dados}

De acordo com os objetivos do estudo, e uma vez que é importante num estudo de caso o acesso a múltiplas fontes de informação (Yin, 2011), as técnicas de recolha de dados selecionadas foram a análise de documentos e a entrevista.

Numa fase inicial do estudo, e com o objetivo de conhecer mais aprofundadamente os valores e outras características do sistema prisional português, assim como as principais tarefas dos guardas prisionais, foi consultada alguma da legislação relacionada com a Direção Geral de Reinserção e Serviços Prisionais (2020) que se considerou relevante para o tema em estudo². Também se visitou a página web do Sindicato do Corpo da Guarda Prisional, de modo a conhecer melhor a história, os valores, as características, as funções e as reivindicações explícitas do sistema prisional português e dos guardas prisionais Além disso, foram analisados alguns blogs e páginas das redes sociais (grupos) ligadas a este grupo profissional o que permitiu obter informações sobre as suas opiniões, reivindicações e preocupações. Da abordagem interpretativa (Jupp \& Norris, 1983 cit in Bloor \& Wood, 2006) destes documentos foi possível obter um conjunto de informações altamente valiosas, nomeadamente a de que os guardas manifestavam explicitamente dificuldade em conciliar simultaneamente o papel de "cárcere" e o de agente de ressocialização. Este dado foi uma mais-valia para compreender a pertinência desta investigação, não unicamente para a produção de conhecimento, mas, acima de tudo, era tida como necessária e valiosa para o grupo profissional que visava investigar.

\footnotetext{
2 A saber: a Orgânica da Direção-Geral de Reinserção e Serviços Prisionais (Despacho n. 8140-A/2019, de 13 de setembro, republicado pela; Declaração de Retificação n.. 863/2019, de 7 de novembro - Constituição de equipas multidisciplinares; Despacho n. 8140 -B/2019, de 13 de setembro - Criação e definição das competências das unidades orgânicas flexíveis; Portaria n.o 300/2019, de 11 de setembro - Fixa a estrutura nuclear dos serviços centrais da DGRSP; Decreto-Lei n.ำ 215/2012, de 28 de setembro -Aprova a Lei orgânica da DGRSP; Declaração de Retificação n.. 63/2012, de 9 de novembro - Retifica o disposto no n. ${ }^{\circ} 1$ do artigo 4. o da Lei orgânica da DGRSP; Portaria n.o $286 / 2013$, de 9 de setembro - Define a estrutura orgânica, regime de funcionamento e competências dos órgãos e serviços dos Estabelecimentos Prisionais); (2) o Regulamento interno (Despacho n. - 3624/2019, de 1 de abril - Regulamento Interno da Direção-Geral de Reinserção e Serviços Prisionais; (3) o Estatuto do Pessoal do Corpo da Guarda Prisional (Decreto-Lei n.o 3/2014, de 9 de janeiro - Aprova o Estatuto do Pessoal do Corpo da Guarda Prisional; Despacho n.o 7109/2015, de 29 de junho - Regulamento da Guarda, Segurança e Conservação de Equipamentos e Armamento da DGRSP; Portaria n.o 247/2015, de 17 de agosto - Modelo de Cartão de Identificação dos elementos do Corpo da Guarda Prisional); (4) o Código da Execução das Penas e Medidas Privativas da Liberdade (Lei n.o 115/2009, de 12 de outubro); (5) o Regulamento Geral dos Estabelecimentos Prisionais (Decreto-Lei n.ํ 51/2011, de 11 de abril); e (6) a Classificação dos Estabelecimentos Prisionais (Portaria n.ํㅜ 13/2013, de 11 de janeiro). Também foram analisados alguns dos documentos que se encontram, em acesso público, na página web da DGRSP, designadamente, a Carta de Missão, o Quadro de Avaliação e Responsabilização (QUAR), o Plano e Relatório de atividades, o Balanço social, a Contratação Pública e Gestão Patrimonial, e os Recursos Financeiros e Humanos desta organização.
} 
Com base nas informações recolhidas a partir da análise de documentos, da entrevista exploratória e da revisão da literatura efetuada, elaborou-se de raiz um guião de entrevista semiestruturada constituído por um conjunto de perguntas abertas formuladas a partir do objetivo e das questões de investigação (Sampieri et al., 2014). Este guião foi validado através de duas entrevistas piloto (gravadas em sistema áudio e posteriormente transcritas), de modo a testar o instrumento (Bardin, 2011). Na sequência destas entrevistas, foi reformulada a redação de algumas das questões consideradas pouco compreensíveis como também foi decidido introduzir no início do guião um pequeno texto introdutório sobre os valores, dada a dificuldade dos guardas - nas entrevistas exploratória e piloto -, em identificar e diferenciar 'valores pessoais e organizacionais'.

A versão final do guião da entrevista é composta por três partes: a primeira parte onde era explicado ao participante o objetivo do estudo e clarificadas todas as questões relativas à confidencialidade da investigação; a segunda, constituída por questões biográficas e profissionais, nomeadamente, o sexo, a idade, estado civil, habilitações literárias, antiguidade na função de guarda prisional, antiguidade no estabelecimento prisional atual e o nível de segurança do estabelecimento prisional em que o participante trabalha atualmente, de modo a caracterizar os participantes do estudo; e, por fim, a terceira parte constituída por um pequeno texto acerca da temática estudada, seguido de um conjunto de perguntas abertas. 0 texto tinha como principal objetivo tornar claro para os participantes alguns dos conceitos centrais deste estudo, nomeadamente, o de stress ocupacional (distress e eustress), os valores individuais e organizacionais e os principais valores que caracterizam o sistema prisional e os estabelecimentos prisionais portugueses - punir/vigiar e ressocializar (Cardoso, 2014; DGRSP, 2020). As perguntas abertas pretendiam explorar os valores pessoais e organizacionais que são reconhecidos pelos guardas prisionais e compreender, a partir da descrição de situações concretas, o modo como os participantes percecionam a existência de $P$ - $O$ fit e conflito de valores, e o impacto que tal tem no stress que por eles é vivenciado.

\section{Procedimento}

Os documentos consultados foram acedidos através da internet e a informação por eles fornecida mostrouse relevante para a compreensão do enquadramento legal e institucional da função em estudo como referimos anteriormente. Com este conhecimento, e tendo em consideração as características da população e dos estabelecimentos prisionais, deu-se início ao contacto com os guardas prisionais. Foi estabelecido o contacto formal com os participantes através de correio eletrónico, a partir do qual lhes foi enviado um pedido de colaboração; posteriormente, acordou-se o local e a hora das entrevistas. Uma vez que se pretendia ter uma amostra com guardas prisionais de estabelecimentos prisionais com diferentes níveis de segurança, algumas das entrevistas foram realizadas por videochamada, via Skype.

Antes de se iniciar a entrevista, apresentou-se, oralmente e por escrito, o objetivo do estudo, afirmando o caráter confidencial e voluntário da participação, e a possibilidade de desistência a qualquer momento da entrevista. Os participantes tiveram igualmente a informação de que os dados iriam ser unicamente utilizados para fins de investigação científica. Os participantes preencheram um consentimento informado relativamente à sua participação no estudo e à autorização para registo áudio das entrevistas.

\section{Técnica de Análise dos Dados}

Recolhidos os dados e validadas as entrevistas por todos os participantes, foi realizada uma pré-análise do material recolhido através da sua leitura flutuante (Bardin, 2011). De seguida, procedeu-se à redução dos dados (Miles \& Huberman, 1994), recorrendo-se à análise de conteúdo temática (Bardin, 2011; Sampieri et al., 2014) que permite fazer uma descrição e interpretação objetiva e organizada do conteúdo de um grande volume de informação não estruturada (Bardin, 2011). Todo o material que constituiu o corpus de análise, documentos e transcrições das entrevistas, foram inseridos no software de análise qualitativa NVivo, versão 11 (QRS), onde se procedeu à categorização e à codificação das informações recolhidas de modo a ser efetuada a análise de conteúdo temática.

A fim de testar a consistência do sistema de categorias ao nível da clareza e da coerência das definições operacionais das categorias, procedeu-se à validação inter-codificadores. Deste modo, foi partilhado com outro investigador $10 \%$ do material a codificar, bem como o sistema de categorias, tendose alcançado - usando a ferramenta coding comparasion query do software NVivo -, uma percentagem de concordância de $96 \%$, o que indica uma boa consistência do sistema de categorias e codificação (Miles \& Huberman, 1994). 


\section{RESULTADOS E DISCUSSÃO}

\section{Redução da Informação}

A informação foi tratada através do processo de codificação, o que implicou a criação de um sistema de categorias (Bardin, 2011) desenhado e concebido a partir dos temas emergentes da revisão da literatura e das entrevistas - sistema de categorias criado a partir de uma lógica dedutiva e indutiva (Bardin, 2011). Por forma a garantir a qualidade das categorias definidas, procurou-se que estas fossem exclusivas, homogéneas, pertinentes, objetivas e exaustivas (Bardin, 2011). No final, obteve-se um sistema com um total de 31 categorias: 10 categorias livres, as Free Nodes, e 21 categorias interligadas, as Tree Nodes (cf. Apêndice). Estas, incluem 3 categorias gerais de primeiro nível e 18 subcategorias (6 de segundo nível, 10 de terceiro nível e 2 de quarto nível).

\section{Os valores pessoais e organizacionais reconhecidos pelos guardas prisionais}

Valores pessoais. A partir dos relatos dos participantes relativamente aos seus valores pessoais (c.f. Tabela 2), é possível identificar dois padrões de resposta distintos: um padrão claramente punitivo representado pelo P04 e um padrão misto (orientação punitiva e reabilitativa) representado pelos restantes participantes. Como tal, ao contrário do que a maioria da literatura fazia prever (Edward \& Cable, 2009), esses valores não se encontram necessariamente em extremos opostos de um continuum - punição vs. ressocialização (Zhang et al., 2018) -, mas formam dimensões relativamente independentes que interagem entre si correspondendo ao preconizado pelo modelo de pluralidade de valores (Tetlock et al., 1996). Deste modo, "valores aparentemente conflituosos, não são mutuamente exclusivos ou de natureza dicotómica", podendo ser mantidos, simultaneamente, valores que aparentam ser contraditórios e incompatíveis entre si, para a maioria dos indivíduos (Zhang et al., 2018, p. 28).

Tabela 2. Reconhecimento dos Valores Pessoais

\begin{tabular}{|c|c|}
\hline Participantes & Verbalizações \\
\hline P01 & $\begin{array}{l}\text { "Mas claro que as pessoas também devem de ser responsabilizadas pelos crimes que } \\
\text { cometeram e viver com as consequências dos seus atos. Agora acho que a punição sem } \\
\text { qualquer ressocialização é errada"; "Eu acredito na ressocialização dos reclusos, e } \\
\text { considero que a prisão acaba por ser uma parte importante nesse processo". }\end{array}$ \\
\hline P02 & $\begin{array}{l}\text { "Sou a favor da ressocialização, mas a punição vem primeiro"; "Para mim está a segurança } \\
\text { acima de tudo, haja o que houver é preferível que haja segurança." }\end{array}$ \\
\hline P03 & $\begin{array}{l}\text { "A prisão também tem que punir, não é?"; "Eu acredito na ressocialização, e acho que ela tem } \\
\text { a mesma importância que a punição e a vigilância...". }\end{array}$ \\
\hline P04 & $\begin{array}{l}\text { "É preciso que as pessoas sejam castigadas pelo que fizeram e eu tenho a obrigação de } \\
\text { garantir isso mesmo, mais nada. Para mim as prisões são indispensáveis para que exista ordem } \\
\text { social. As prisões servem para tornar o mundo mais seguro"; "Se quer que lhe seja sincero conto } \\
\text { pelos dedos das mãos aqueles [reclusos] que realmente merecem uma segunda oportunidade". }\end{array}$ \\
\hline P05 & $\begin{array}{l}\text { "Tento ver um bocadinho o lado deles [reclusos], e eu estou ali para ouvir e para tentar } \\
\text { ajudar naquilo que eu posso."; "Também depois o facto de ver as regalias que os presos têm, } \\
\text { também faz com que acabe por desempenhar um papel mais punitivo". }\end{array}$ \\
\hline P06 & $\begin{array}{l}\text { "Eu acredito que, por vezes, é necessário usar a força."; "As regras são a coisa mais importante } \\
\text { dentro de uma prisão. São elas que fazem com que a ordem e a segurança sejam mantidas dentro } \\
\text { da prisão"; "Eu apenas faço isso porque me sinto bem comigo mesmo e sei que é o certo a fazer. } \\
\text { Se vemos que uma pessoa não está bem, vamos ignorar? Eu tento ajudar a pessoa porque } \\
\text { acredito que a posso ajudar..." }\end{array}$ \\
\hline P07 & $\begin{array}{l}\text { "E é acho que só partindo deste princípio: que tudo bem as pessoas erram, cometem crimes e tal, } \\
\text { mas que têm a capacidade de mudar, que podes fazer o trabalho de ressocialização que as } \\
\text { reclusas precisam"; "Eu até considero que somos, por vezes, um pouco benevolentes para as } \\
\text { reclusas.". }\end{array}$ \\
\hline P08 & $\begin{array}{l}\text { "Se me focar mais até na questão que aquele individuo, hum, tem direito à ressocialização e } \\
\text { que tentando perceber o individuo como um todo, mais fácil é de desempenhar a função } \\
\text { voltada para a vigilância, para a segurança."; "Eu não sou juiz. O juiz já determinou, a mim apenas } \\
\text { me compete fazer com que eles cumpram. E não sou eu que vou julgar aquele individuo." }\end{array}$ \\
\hline
\end{tabular}

O modelo do pluralismo de valores (Tetlock et al., 1996), tal como a teoria da dissonância cognitiva (Festinger, 1957), preconiza que quando os valores conflituosos são de importância desigual, os indivíduos tendem a negar o valor menos importante e reforçar o valor mais importante (Festinger, 1957; Tetlock et al., 1996) de modo a reduzir o desconforto derivado deste conflito interno, tal como é evidenciado em P02. Todavia, P03 valoriza igualmente a punição e a ressocialização. Nestas situações, este modelo refere que 
quando ambos os valores são de alta importância, alguns indivíduos podem usar um raciocínio complexo integrador que os combina num nível superior (Tetlock et al., 1996). Neste sentido, os guardas prisionais podem não considerar a punição/vigilância e ressocialização como valores incompatíveis e mutuamente exclusivos tendendo a considerar a ordem e a segurança como fatores essenciais para a criação de um ambiente favorável à aplicação de um meio benéfico e propício à adoção de um tratamento penitenciário favorável à ressocialização (Zhang et al., 2018), como é exemplificado por P08.

Valores organizacionais. Ao observar a Tabela 3 verifica-se que os participantes distinguem dois tipos de valores organizacionais: os valores do sistema prisional em geral e os valores do seu estabelecimento prisional.

Tabela 3. Reconhecimento dos Valores Organizacionais

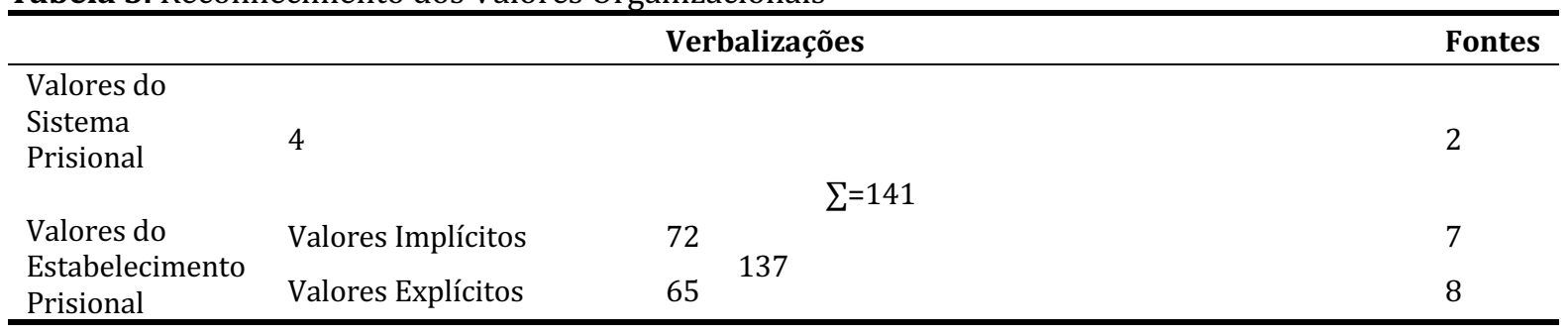

Segundo Butler et al. (2019), para a maioria dos guardas prisionais os valores do sistema prisional são mais abstratos e gerais do que servem para guiar o funcionamento dos estabelecimentos prisionais e socializar os novos guardas prisionais, o que é bem ilustrado por P01"Eu sei que os valores do sistema prisional em geral é castigar os reclusos que cometeram um crime e ao mesmo tempo dar-lhe as competências e os meios necessários para que eles possam voltar a inserir-se na sociedade". Como tal, os guardas prisionais tendem a encarar os valores do sistema prisional como valores teóricos e os valores do estabelecimento prisional como valores práticos, que traduzem a idiossincrasia de cada estabelecimento prisional (e.g. nível de segurança e grau de complexidade de gestão) e de quem ocupa os cargos de chefia (Cardoso, 2014). Exemplo disto são as afirmações de P06 "Por isso é que eu acho que apesar de o sistema prisional ter como valores o punir e o ressocializar, depois o modo e o grau em que cada uma destas coisas é feita, acaba por variar consoante as características da prisão e dos reclusos e também do próprio diretor e dos chefes". Tornou-se, assim, necessário estabelecer duas categorias de terceiro nível que evidenciassem esta diferenciação dos valores do estabelecimento prisional: valores implícitos e valores explícitos. Apresentase na Tabela 4 algumas verbalizações relativas a estes dois tipos de valores.

Tabela 4. Valores do Estabelecimento Prisional (EP)

\begin{tabular}{ll}
\hline Valores do EP & Verbalizaçães \\
\hline Valores & "Se eu sinto que o meu estabelecimento não me leva, ou leva muito pouco, a ter \\
Explícitos & comportamentos que promovam essa ressocialização, acho que estaria a mentir se \\
& dissesse que acredito que um dos valores do meu estabelecimento é a ressocialização. A \\
& punição sim, sim, sem dúvida!" P01 \\
& "Ajudamos na parte da reinserção e ao mesmo tempo mantemos a segurança e a \\
& vigilância nos reclusos. Obvio que entre um e outro, o primeiro é a segurança." P02 \\
& "Tal como a minha organização diz, a ressocialização não é o nosso principal valor." P04 \\
& "A minha prisão preocupa-se muito mais com a reinserção do que com a punição." P06 \\
& "Os valores do meu estabelecimento prisional, tal como os valores do sistema prisional, são, \\
& a ressocialização dos reclusos, de modo a promover a sua reinserção na sociedade depois de \\
& estes terem cumprido a pena, e a vigilância, ou seja, garantir a segurança do estabelecimento \\
& prisional." P08 \\
"Porque às vezes as decisões são fundamentadas naquilo que eles (chefes) acham melhor... os \\
valores pessoais dos chefes, e não aquilo que está escrito. Mesmo que contradigam o que \\
Implícitos \\
está escrito." P02 \\
“Queremos fazer aquilo que aprendemos no curso, mas o problema é que depois tu tens \\
que fazer o que o teu superior hierárquico te manda fazer, por quem manda, pelos \\
superiores, que interpretam as coisas à maneira deles."; "É um bocadinho da vigilância, um \\
bocadinho o que eles querem ainda. Porque os superiores são muito mais velhos e ainda \\
estão muito no modelo da punição, é punição, é punição." P05
\end{tabular}


Tal como referem Costa et al. (2017), verifica-se dentro da prisão a existência de uma estrutura interna com valores formais e informais, implícita, que se configura numa cultura particular capaz de promover a reabilitação dos reclusos ou o reforço de uma orientação punitiva. No entanto, também se pode concluir que, na maioria dos estabelecimentos prisionais analisados, a pena tem cumprido apenas o seu caráter retributivo, apenas impondo um castigo ao condenado, sem lhe proporcionar a sua recuperação e consequente reinserção social. Existe, então, uma discrepância entre os valores explícitos dos estabelecimentos prisionais e os valores implícitos dos mesmos. Tal poderá traduzir o problema de delegação de autoridade identificado por Selznick (1949), característico de várias organizações com um modelo de gestão burocrático. Tal leva a que a organização burocrática se afaste cada vez mais dos valores formais da organização, centrando-se nos valores informais dos subgrupos dos estabelecimentos prisionais, ou seja, no "modelo do carcereiro" (Pereira, 2011).

\section{Perceção de congruência de valores pelos guardas prisionais}

Ao observar a tabela 5, verifica-se que a congruência de valores, tal como é percecionada pelos participantes deste estudo, pode manifestar-se através do fit, misfit e conflito de valores, de acordo com o modelo da congruência de valores proposto por Liedtka (1989).

Tabela 5. Congruência de Valores

\begin{tabular}{|c|c|c|c|c|c|}
\hline \multirow{2}{*}{ P-O Fit Subjetivo } & \multirow[b]{2}{*}{ Fit } & \multicolumn{3}{|c|}{ Verbalizações } & \multirow{2}{*}{$\frac{\text { Fontes }}{8}$} \\
\hline & & 50 & \multirow{2}{*}{94} & \multirow{4}{*}{$\sum=169$} & \\
\hline \multirow{3}{*}{$\begin{array}{l}\text { Conflito de Valores } \\
\text { Percecionado }\end{array}$} & Misfit & 44 & & & 7 \\
\hline & $\begin{array}{l}\text { Conflito Punir-Vigiar e } \\
\text { Ressocializar } \\
\text { Conflito no Grau de }\end{array}$ & 48 & \multirow[t]{2}{*}{75} & & 5 \\
\hline & $\begin{array}{l}\text { Punição-Vigilância e } \\
\text { Ressocialização }\end{array}$ & 27 & & & 5 \\
\hline
\end{tabular}

Verifica-se uma predominância de $P$-O fit subjetivo (56\%), comparativamente ao conflito de valores percecionado pelos guardas prisionais (44\%). Tal poderá indicar que na amostra estudada os indivíduos evidenciam um fit ligeiramente maior entre os seus valores pessoais e os valores da sua organização do que conflito entre estes dois tipos de valores.

Perceção de P-0 fit subjetivo pelos guardas prisionais. Tal como está representado na Tabela 5, existe uma relativa superioridade de verbalizações relativas ao Fit (53\%), comparativamente às de Misfit (47\%). Por outro lado, todos os participantes verbalizaram, em alguma altura, perceções de fit entre os seus valores pessoais e os valores do seu estabelecimento prisional. Seria de esperar, tal como referem Lambert et al. (2019), que os guardas prisionais percecionassem fit quando os seus valores pessoais fossem similares aos valores do estabelecimento. Todavia, a maioria dos participantes acaba por percecionar o seu P-O fit de um modo distinto do que a maioria dos autores fazia prever (e.g. Edwards \& Cable, 2009), uma vez que, e tal como já foi referido anteriormente, encaram os valores punir/vigiar e ressocializar como valores independentes (Butler et al., 2019). Tal leva a que estes possam percecionar um fit distinto para cada um destes valores, ou seja, é possível que um guarda prisional percecione simultaneamente um elevado fit a nível da ressocialização e um elevado misfit a nível da punição ou vice-versa.

Por outro lado, ao nível do misfit subjetivo, sete dos oito participantes verbalizaram perceções de misfit entre os seus valores pessoais e os valores organizacionais. Neste sentido, as verbalizações dos participantes vão ao encontro do defendido por Ramos e Jordão (2013) de que "a falta de fit entre os valores individuais e organizacionais não é sinónimo de misfit ou conflito" (p. 17), uma vez que as diferenças cognitivas que se podem encontrar entre o fit e o misfit são categorias independentes e não necessariamente contraditórias (Ramos \& Jordão, 2013). Assim, e tal como o P04 refere (cf. Tabela 6), o indivíduo pode sentir que existe uma fraca correspondência entre os seus valores e os da organização, sem que tal signifique, obrigatoriamente, a perceção de um conflito entre as partes (Ramos \& Jordão, 2013). Desta forma, o misfit nos guardas prisionais, e tal como P07 esclarece, sucede quando os valores da organização não são apoiados pelo trabalhador, manifestando-se a partir de uma subordinação dos valores pessoais dos guardas prisionais aos valores implícitos do seu estabelecimento prisional. Tal, considerando Pereira (2011), pode dever-se ao facto de os estabelecimentos prisionais serem organizações altamente militarizadas e burocratizadas, fundamentadas, acima de tudo, no respeito pela hierarquia. 
Tabela 6. P-O fit Subjetivo

\begin{tabular}{cl}
\hline $\begin{array}{c}\text { P-O fit } \\
\text { subjetivo }\end{array}$ & Verbalizações \\
\hline & "Segurança acima de tudo, vigilância acima de tudo... e identifico-me mesmo com isso." P02 \\
& "No geral, eu penso que a organização acaba por ir de encontro ao que eu acredito..." P03 \\
"Sem dúvida que sinto que os meus valores são semelhantes aos do meu estabelecimento." P04 & "A nível da ressocialização concordo, até porque existem aqueles programas para isso" P07 \\
& "Porque há o guarda que ainda pensa à moda do carcereiro e depois há aquele guarda que já não \\
& pensa tanto assim, e procura, realmente, ir de encontro aos valores que a própria instituição \\
defende, não é? Como eu." P08
\end{tabular}

Perceção de conflito pelos guardas prisionais entre os seus valores individuais e os valores organizacionais reconhecidos. Ao contrário do que o modelo de congruência de valores de Liedtka (1989) defende, o conflito de valores percecionado pelos guardas prisionais entrevistados, não ocorre somente quando o trabalhador perceciona os valores pessoais e os valores organizacionais como contraditórios, mas ocorre, igualmente, em situações em que os indivíduos percecionam conflito entre o grau de punição/vigilância e ressocialização que defendem, e o grau aplicado pela sua organização (cf. Tabela 7).

Tais dados, vêm mais uma vez, corroborar a pertinência da aplicação do modelo da pluralidade de valores, que defende que os indivíduos, tal como as organizações, podem perseguir, simultaneamente, valores aparentemente contraditórios (Zhang et al., 2018). Assim, os valores individuais entram em conflito com os valores organizacionais, não só por estes serem opostos entre si, mas também devido ao facto de os guardas prisionais percecionarem que o seu estabelecimento prisional não pune/vigia ou ressocializa os reclusos no grau que eles acreditam ser o mais indicado. Ao analisar as verbalizações da Tabela 7, verificase que um dos motivos pelos quais existe conflito de valores deve-se ao facto, e tal como P02 refere, de os guardas prisionais percecionarem um conflito entre os seus valores pessoais e os valores implícitos e explícitos da organização. 
Tabela 7. Conflito de Valores

\begin{tabular}{|c|c|}
\hline Conflito de valores & Verbalizações \\
\hline \multirow{4}{*}{$\begin{array}{l}\text { Conflito Punir - Vigiar } \\
\text { e Ressocializar }\end{array}$} & $\begin{array}{l}\text { "Sabes que nem sempre sentimos que os nossos valores sejam compatíveis com os do } \\
\text { nosso estabelecimento prisional é naturalmente necessário colocares os teus } \\
\text { valores de lado, para fazeres o que o teu estabelecimento prisional espera de ti" }\end{array}$ \\
\hline & $\begin{array}{l}\text { "Uma coisa é o que eu acho que deve de ser feito, outra coisa é o que o chefe acha } \\
\text { que deve ser feito, e outra coisa é o que está escrito que deve ser feito." P02 }\end{array}$ \\
\hline & $\begin{array}{l}\text { "Eu sou dos últimos cursos, eu venho fresquinha, e chego lá e tens de seguir os valores } \\
\text { organizacionais da instituição que não são os mesmos que eu aprendi no curso, e } \\
\text { com os quais me identificava, percebes? Não são. E cria conflito na tua cabeça.";"Às } \\
\text { vezes chamam-me morena porque para mim a Rafaela [nome fictício] é a que está no } \\
\text { trabalho, é como se fosse uma atriz." P05 }\end{array}$ \\
\hline & $\begin{array}{l}\text { "Identifico-me, enquanto guarda prisional e não vamos entrar pela questão da chefia, } \\
\text { não é? Aí os meus valores pessoais colidem com os supostos valores } \\
\text { organizacionais que são impostos pelos meus chefes."; “A minha função exige que } \\
\text { eu seja assim e então confronto, confronto não existe bem. Agora se me perguntar, } \\
\text { entre a Vânia [nome fictício] que não é guarda, aí isso sim" P08 }\end{array}$ \\
\hline \multirow{2}{*}{$\begin{array}{l}\text { Conflito no Grau de } \\
\text { Punição - Vigilância e } \\
\text { Ressocialização }\end{array}$} & $\begin{array}{l}\text { "Se o recluso está sempre a escolher pelo caminho do crime, não devia ser apenas a } \\
\text { pena a ser agravada, deveriam de ser tirados privilégios dentro da prisão. Para } \\
\text { muitos até acham que a pena é umas férias com tudo pago. Eu acho isto mal, muito mal. } \\
\text { Vai contra o que eu acredito." P04 }\end{array}$ \\
\hline & $\begin{array}{l}\text { "A minha prisão torna a vida deles completamente facilitada e eles não têm, } \\
\text { realmente, de pagar pelo que fizeram porque até lá dentro lhes é feita a papinha } \\
\text { toda. É ridículo, faz-me uma confusão que nem imaginas..."; "Porque eu sinto que não } \\
\text { posso punir nem ressocializar como deveria... é muito difícil encontrar uma } \\
\text { situação em que tenha feito as coisas como acho que deveriam de ser feitas." P05 }\end{array}$ \\
\hline
\end{tabular}

Neste sentido, salienta-se que, na maioria dos casos, os participantes apenas percecionam um conflito entre os seus valores pessoais e os valores explícitos do seu estabelecimento prisional em relação ao grau de punição/vigilância e/ou ressocialização. Por outro lado, as verbalizações demonstram que os participantes tendem a percecionar conflito entre os seus valores pessoais e os valores implícitos da sua organização quando existe um confronto entre os seus valores individuais e os valores dos seus chefes valores implícitos.

\section{Relação entre a congruência de valores e o stress vivenciado pelos guardas prisionais}

Analisando o papel da congruência de valores, entre os valores pessoais dos guardas prisionais e os valores da sua organização, destaca-se o facto de esta variável se ter assumido como um dos fatores que potenciam o stress ocupacional nesta função (c.f. Tabela 8).

Tabela 8. Relação entre a Congruência de Valores e o Stress Ocupacional

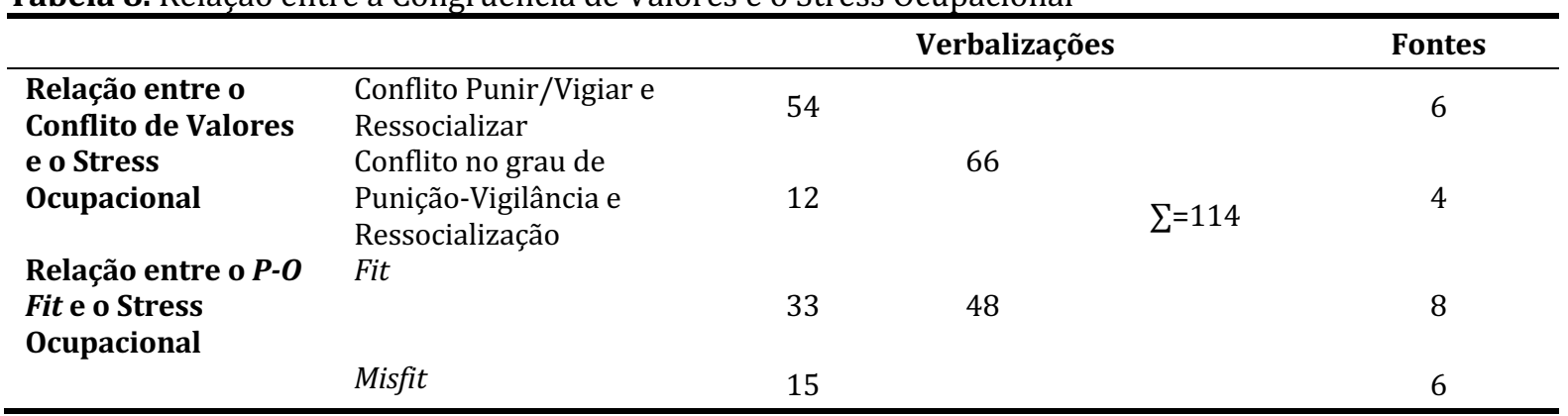

Tal também foi verificado em outros estudos (por ex. Edwards \& Cable, 2009; Ramos \& Jordão, 2013), que demonstraram que o conflito de valores é um importante preditor de stress ocupacional. Por outro lado, é possível verificar que existe mais verbalizações que associam o conflito de valores (58\%) do que o $P$-O fit (42\%) ao stress ocupacional. Assim, a partir dos resultados obtidos foi possível esclarecer que o fit e o misfit entre os valores pessoais dos guardas e os valores do seu estabelecimento prisional são aspetos cognitivos independentes (Ramos \& Jordão, 2013), e que a ausência de fit entre estes dois tipos de valores não é sinónimo de conflito entre a organização e o guarda prisional. 
Relação entre o P-O fit subjetivo e o stress vivenciado pelos guardas prisionais. Através das verbalizações apresentadas na Tabela 9, pode-se concluir que a perceção de $P$ - $O$ fit leva a que os guardas prisionais percecionem menos distress e mais eustress.

Tabela 9. Relação entre o P-O Fit Subjetivo e o Stress Ocupacional

"Não senti stress... pelo menos aquele stress mau. Existir este alinhamento fez com que eu encarasse a situação de uma melhor maneira. Talvez tenha sentido um stress bom." P01

"Claro que sentir que a nossa organização aprova o que fazemos nos leva a sentir bem com o nosso trabalho. Dá-nos um sentido ao que fazemos, isso acaba por nos dar força e uma certa energia para continuar." P02

"E só posso dizer que nestas situações sinto-me bem comigo mesmo. Sinto que faço algo que me ajuda a continuar e a ser melhor na minha profissão. Sinto-me realizado, pois sei que estou a fazer o que devo e o que esperam que eu faça. É como se estes momentos me dessem uma força extra para continuar a melhorar." P03

Fit "Ajuda a que eu sinta menos stress, claro. Ou que talvez sinta aquele stress bom. Sentirmos que é o certo a fazer, dá-nos uma certa energia. Sinto-me muito mais determinado e o trabalho torna-se mais fácil." P04

"Saber que aceitamos o que nos mandam fazer, não porque somos obrigados, mas porque acreditamos que aquilo é o certo... as coisas são feitas com muito mais ânimo... dá-nos outra energia. É difícil de explicar, mas ajuda a dar sentido ao nosso trabalho e ajuda-nos a levantar da cama para irmos trabalhar todos os dias." P07

"Quando há essa harmonia? Aí desenvolve aquele stress que me falou que é positivo, não é? Uma pessoa sente-se gratificada e sente o que o nosso trabalho é, de alguma forma, reconhecido e vai de acordo aquilo que nós, lá está, que nós sentimos e que ansiamos." P08

"O que eu acredito por vezes é um bocado diferente do que a minha organização acredita. Acho que é normal isso acontecer e acho que não vem mal ao mundo por isso! Pelo menos eu não me sinto mal com isso" P03

Misfit "Não é o que me causa stress no meu trabalho, até porque isto são casos pontuais, e na maioria das vezes acredito que eu e a minha organização estamos em harmonia." P04

"Isso de os valores serem às vezes diferentes, sei separar muito bem... dou-me muito bem porque tenho um bom jogo de rins. Não é uma coisa que me vai afetar muito. Em termos de stress não me stressa nada." P06

Neste sentido, tal como proposto no modelo $P$-E fit (French et al., 1982), quando os valores do guarda prisional e os do seu estabelecimento prisional são similares surgem consequências positivas para estes indivíduos, nomeadamente menores níveis de stress, uma vez que os guardas consideram que têm os recursos necessários para fazer face às exigências da sua organização (Edwards \& Cable, 2009). A partir dos dados obtidos, podemos admitir que os guardas prisionais capazes de compatibilizar os valores punir e ressocializar sejam mais eficientes a lidar com as exigências da organização. Na verdade, estes trabalhadores podem resistir a este conflito de valores devido ao facto de acreditarem tanto na ressocialização como na punição/vigilância, podendo, assim, ser capazes de gerir este potencial conflito de valores por não considerarem necessariamente a reabilitação e punição como inerentemente incompatíveis, sendo capazes de encontrar significado e valor em ambos os aspetos do seu trabalho e, assim, ser menor o risco de experienciarem stress ocupacional (Zhang et al., 2018). Simultaneamente, o facto de os guardas prisionais deterem estes dois valores pode potenciar o aumento do interesse e da motivação dos trabalhadores em relação ao seu trabalho, o que pode levar a que estes interpretem as exigências do seu trabalho como desafiantes e não limitativas, pelo que o indivíduo se sente autoconfiante e motivado para ultrapassar as dificuldades. Tal é evidenciado por alguns participantes que verbalizaram experienciar um "stress bom" quando percecionam P-O fit. Neste sentido, os guardas prisionais podem considerar que este tipo de congruência de valores pode assumir uma forma positiva e benéfica, representando uma condição de stress que é dinamizadora e que contribui para o seu progresso, constituindo, assim, uma fonte de eustress (Cardoso, 2014).

Por outro lado, a partir das verbalizações relativas ao papel do misfit na vivência do stress ocupacional pelos guardas prisionais, foi possível constatar que este misfit não tem um papel preponderante na experiência de stress ocupacional por estes profissionais, uma vez que, em última instância este misfit irá conduzir a um reajustamento de valores, normalmente por parte do trabalhador (Liedtka, 1989). Apesar de ainda não terem sido desenvolvidas teorias que expliquem o modo através do qual o misfit conduz a resultados distintos do fit, Ramos e Jordão (2013) reconhecem que é possível estarem associados ao misfit um conjunto de processos psicológicos distintos dos relacionados com o fit. 
Relação entre o conflito de valores e o stress vivenciado pelos guardas prisionais. A partir das verbalizações da Tabela 10 é possível verificar que o conflito de valores tem um papel preponderante na vivência negativa do stress ocupacional pelos guardas prisionais.

Tabela 10. Relação entre o Conflito de Valores e o Stress Ocupacional

"Sinto que o facto de os meus valores entrarem em conflito com os valores da minha organização me deixa, claro, muito stressada. E a maioria das vezes eu não sei lidar com isso."; "Haverá situações mais stressantes no trabalho do que aquela que te levam a fazer coisas no teu dia a dia, na tua hora a hora, no teu minuto a minuto de trabalho, que te levam a duvidar de ti mesmo? E que te leva a pôr em causa o teu próprio caráter? Para mim não..." P01

"Imagine o dia inteiro a passar por situações dessas, em que temos que pôr em prática ordens que vão contra os nossos valores (...) é stressante para nós, não é? E isso desgasta e stressa."; "E quando discordamos com o que está escrito, ainda é naquela, porque sabemos que aquilo foi visto e revisto por várias pessoas e que chegaram a um consenso. 0 pior é quando discordamos com o que o nosso superior acha que deve

Conflito Ressocializar Punir/Vigiar e

de ser feito... aí fico muito mais stressada." P02

"Não tens hipótese... porque quem está acima de ti já trabalha de uma determinada maneira e tem aquilo tão vincado, que tu estás lá sem poderes fazer nada e isso não te faz sentir nada bem... causa distress, percebes? É todos os dias vires para casa, a chorar e a rebentar porque os teus valores são estes e estás a ir contra aquilo que tu acreditas e que aquilo que tu queres fazer.”; “É muito stress, muito stress. São noites sem dormir mesmo, "pesadelar" com isso, porque aquela porcaria é difícil. Este confronto de valores diário é muito difícil de lidar." P05

"É isso que nos causa o stress... quando os meus valores enquanto Vânia [nome fictício] cidadã chocam com os valores da minha organização."; "Porque eu considero que os meus valores pessoais são idênticos aos da minha organização. 0 stress não advém daí. Advém do facto de os meus chefes deturparem tudo e fazerem com que os seus valores pessoais, se tornem os valores da minha organização. Isso é que é o real fator de stress na minha profissão." P08

"Deixa-me chateada e stressada... $\mathbf{E}$ isso depois acaba por ser desgastante a longo prazo... é cansativo. E depois as pessoas acabam por deixar de se chatear... deixam andar... aprendem a lidar com isso. Pelo menos comigo é assim. Agora isso passa-me um pouco ao lado." $P 01$

Conflito Grau de Punição/Vigilância e Ressocialização
"É deixar andar e ires contra ti própria, percebes? É tipo uma dicotomia, não dá, não te chateies. Mas custa, é stressante." P05

"É bastante desgastante e stressante pensar que podíamos fazer mais e melhor para garantir a segurança do nosso estabelecimento e de quem trabalha lá dentro." P07

Estas evidências confirmam que o impacto negativo da congruência de valores se manifesta a partir do conflito entre os valores individuais e os valores organizacionais (Ramos \& Jordão, 2013). Tal como Edwards e Cable (2009) defendem, o facto de o trabalhador percecionar que não tem os recursos necessários para fazer face às exigências que advêm deste conflito de valores, leva a resultados negativos, nomeadamente ao distress. Uma explicação mais detalhada pode ser encontrada na teoria da dissonância cognitiva (Festinger, 1957). Assim, se um guarda prisional apoiar convictamente ambos os tipos de valores - punir/vigiar e ressocializar -, e considerar que no seu dia a dia de trabalho a sua organização não lhe permite pôr em prática as suas crenças, provavelmente tenderá a sentir-se inconsistente e hipócrita. Tal causar-lhe-á dissonância cognitiva, que, por sua vez, gera tensão. Como tal, estes profissionais irão experienciar distress, pois consideram que não possuem os recursos psicológicos necessários para lidar com esta dissonância.

Salienta-se ainda o facto de os participantes terem percecionado um distress maior nas situações em que os seus valores pessoais colidiam não com os valores explícitos da sua organização, mas antes com os valores implícitos da mesma. Tal é particularmente evidente nas verbalizações do P08 que refere que o "real fator de stress" dos guardas prisionais advém do conflito entre os seus valores pessoais e os valores dos seus superiores, uma vez que os guardas prisionais consideram que os seus superiores imediatos têm uma postura de liderança desadequada (Arruda, 2013; Cardoso, 2014).

Finalmente, o conflito no grau de punição/vigilância e ressocialização tende a ser reportado pela maioria dos participantes como menos problemático que a perceção de conflito entre estes dois tipos de valores. Neste sentido, os participantes referem que ao longo do tempo se foram adaptando a estas situações e que, atualmente, já dispõem de mais recursos para lidar com esta incompatibilidade. No entanto, é percetível nas verbalizações destes guardas prisionais uma demarcada desmotivação, uma vez 
que não conseguem atuar como punidor/vigilante e/ou ressocializador no grau que acreditam ser o correto. Assim, e de modo a lidar com a tensão que advém deste conflito, evidenciam descomprometimento organizacional, enquanto mecanismo de defesa (Lambert et al. 2019). Por outro lado, e tal como defendem Lazarus e Folkman (1984), uma vez que a força dos stressores depende maioritariamente do modo como a pessoa os valoriza, é possível que o facto de os guardas prisionais percecionarem este tipo de conflito como menos grave do que o conflito derivado da existência de dois sistemas de valores opostos (individuais vs. organizacionais), leva a que estes não encarem o primeiro como um fator de stress tão preponderante para a vivência do stress ocupacional como o conflito punir/vigiar e ressocializar, uma vez que este não põe em causa a sua autoidentidade (Lambert et al., 2019).

\section{CONCLUSÕES}

Os três principais resultados deste estudo encontram-se esquematizados na Figura 1.

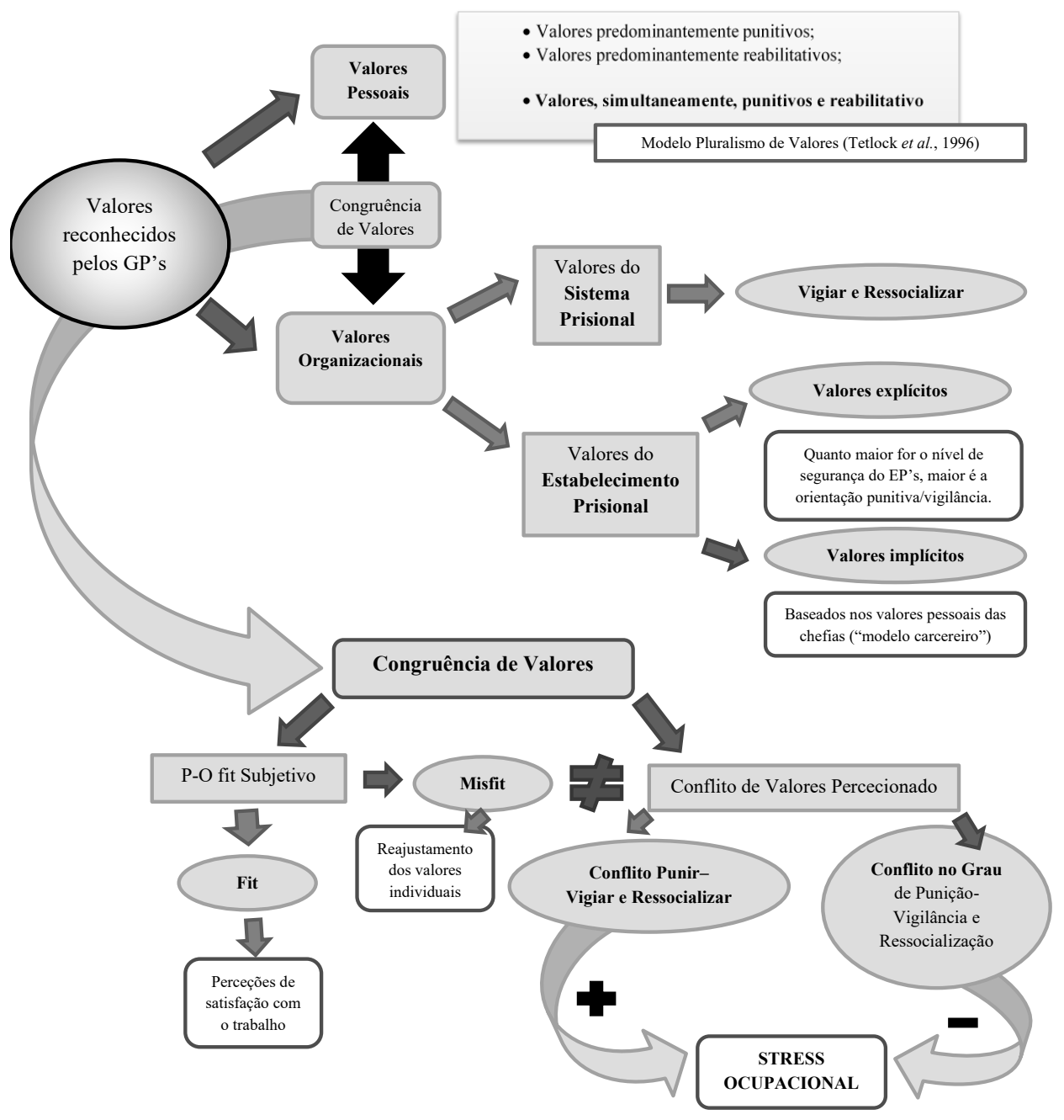

Figura 1. Esquematização gráfica dos resultados alcançados.

Assim, e em primeiro lugar, este estudo permitiu esclarecer que os valores punir/vigiar e ressocializar, ao contrário do que a maioria da literatura organizacional e social fazia prever (Festinger, 1957; Zhang et al., 2018), são encarados pela maioria dos participantes como dimensões relativamente independentes que interagem entre si (Zhang et al., 2018). Torna-se, assim, necessário analisar os valores dos participantes com base no modelo do pluralismo de valores (Tetlock et al., 1996), de modo a ter uma visão aprofundada acerca dos valores individuais reconhecidos pelos guardas prisionais. De facto, a maioria dos guardas prisionais consideram deter estes dois tipos de valores, o que, na maioria dos casos, facilita o seu trabalho. Isto levanta uma questão acerca da definição de valores conflituosos: estarão estes valores, realmente, em conflito se a maioria dos indivíduos não os encara como tal e, consequentemente, pode apoiar ambos? Tal poderá ter implicações na literatura organizacional que, muitas vezes, assume uma 
natureza demasiado simplista dos valores, analisando-os como valores conflituosos, com o objetivo de facilitar o estudo desta variável.

Em segundo lugar, os nossos resultados corroboram as ideias propostas por Ramos e Jordão (2013) e pelo modelo da congruência de valores (Liedtka, 1989), uma vez que a congruência de valores pode manifestar-se através do fit, misfit e conflito de valores. Assim, uma vez que estes três conceitos são independentes, a ausência de fit não é indicador de conflito de valores, pois como os nossos resultados demonstraram, não só estas variáveis não correspondem ao mesmo fenómeno (Ramos \& Jordão, 2013), como também os próprios participantes as interpretam como fenómenos distintos que têm um impacto diferenciado no seu bem-estar e, consequentemente, no tipo de stress ocupacional vivenciado.

Finalmente, importa salientar o facto de os participantes deste estudo verbalizarem dois tipos distintos de conflito: o conflito entre os valores pessoais e os valores organizacionais (punir/vigiar e ressocializar), e o conflito entre o grau em que os guardas prisionais consideram que os reclusos deveriam ser punidos/vigiados e ressocializados e o grau de punição/vigilância e ressocialização aplicado pelo seu estabelecimento prisional. Se o primeiro tipo de conflito aparece frequentemente na literatura (Arruda; 2013; Lambert et al., 2019), até à data não foram encontrados estudos que evidenciassem a existência deste segundo género de conflito. Apesar de o conflito punir/vigiar e ressocializar ter, na opinião dos participantes, um impacto negativo muito maior no stress ocupacional percecionado não se deve menosprezar o impacto que o conflito no grau de punição/vigilância e ressocialização tem no bem-estar destes profissionais, especialmente porque este tipo de conflito parece conduzir ao descomprometimento organizacional, o qual parece ter uma função moderadora na vivência do stress (Butler et al., 2019).

\section{LIMITAÇõES DO ESTUDO E PISTAS PARA FUTURAS INVESTIGAÇÕES}

Os resultados por nós encontrados devem ser lidos considerando algumas limitações. Em primeiro lugar, aponta-se o facto de a variável "valores" ser uma variável difícil de estudar, especialmente quando utilizada uma metodologia qualitativa, uma vez que existe o risco de as respostas dos participantes estarem enviesadas por má interpretação do conceito ou até por alguma confusão com outros conceitos similares, nomeadamente as atitudes (Schein, 2010). Por outro lado, é possível que possa ter havido alguns enviesamentos, tanto por parte dos participantes como das investigadoras na identificação dos valores organizacionais implícitos e explícitos. Salienta-se, assim, que as técnicas utilizadas para o reconhecimento dos valores, na perspetiva dos guardas prisionais, são insuficientes para caracterizar e analisar a cultura de cada um dos estabelecimentos prisionais investigados. Paralelamente, e ainda em relação a esta questão, os participantes podem ter respondido segundo o critério da desejabilidade social, que poderá ter sido potenciado pelo texto introdutório, incluído na terceira parte do guião.

Ainda dentro da temática dos valores, e face aos resultados obtidos acerca da natureza dos valores conflituosos, seria importante desenvolver mais estudos que analisassem a possibilidade de, e ao contrário do que uma grande parte dos autores defende (Festinger, 1957; Zhang et al., 2018), as pessoas serem capazes de apoiar, simultaneamente, valores aparentemente conflituosos e viver com uma certa dose de dissonância cognitiva. Tal poderia ser uma mais-valia para compreender melhor as perceções de congruência de valores e de stress ocupacional numa série de profissões que diariamente lidam com valores conflituosos.

Por último, ressalva-se o facto de os participantes considerarem que a profissão de guarda prisional, apesar de ser uma das mais stressantes do mundo (Afonso e Gomes, 2009; Gonçalo et al., 2010; Moreira, 2016; Roseira, 2017), ser uma das funções mais negligenciadas ao nível da investigação nacional (Cardoso, 2014; Costa et al., 2017; Roseira, 2017). Como tal, a partir das entrevistas realizadas e da análise dos free nodes, foram identificados uma série de outros fatores potenciadores de stress - as más condições de trabalho, a relação com os reclusos, colegas e chefia, horários por turnos, sobrelotação das prisões (que gera sentimentos de insegurança) - que deveriam merecer a atenção dos investigadores portugueses especialmente quando considerados alguns dos acontecimentos recentes ocorridos nos estabelecimentos prisionais (e.g. fuga de reclusos, greves, agressões). Por outro lado, a análise dos free nodes permitiu não só compreender que existe um conjunto de barreiras que dificultam o sucesso do processo de ressocialização e/ou vigilância/punição dos reclusos, como também evidenciou que as características sociodemográficas aparentam ser um dos fatores que podem moderar a vivência do conflito de valores e stress ocupacional pelos guardas prisionais. Neste sentido, a partir das verbalizações dos participantes, emerge a perspetiva de que os indivíduos do sexo feminino, mais novos e/ou com menos anos de serviço tendem a relatar maiores dificuldades em lidar com o conflito entre os seus valores pessoais e os valores da sua organização, evidenciando maiores níveis de stress ocupacional; enquanto indivíduos do sexo masculino, mais velhos e/ou com mais anos de serviço tendem a evidenciar menores níveis de stress ocupacional uma vez que tendem a aceitar e/ou desvalorizar o conflito de valores vivenciado. Por outro lado, os guardas prisionais que trabalham em estabelecimentos prisionais com níveis de segurança mais elevados tendem a 
percecionar menor conflito de valores, e logo menos distress, do que os guardas prisionais que exercem a sua profissão em prisões com níveis de segurança mais baixos.

Tais dados parecem ser uma mais-valia para compreender mais aprofundadamente os motivos pelos quais muitos guardas prisionais "entram nas suas carreiras com elevadas expectativas, motivação e investimento pessoal e sentem-se futuramente defraudados nos seus objetivos e valores" (Cardoso, 2014, p.15). Como tal, consideramos que seria importante desenvolver mais estudos que analisassem o impacto destas variáveis no bem-estar dos guardas prisionais, nomeadamente, na vivência do stress ocupacional e perceção de "satisfação no trabalho".

De uma forma geral, este estudo alerta para a importância de se realizarem investigações no âmbito da cultura organizacional, pois, tal como afirma Schein (2010), esta é baseada em assunções relacionadas com as crenças e valores dos seus membros acerca de como a organização funciona, afetando todo o sistema de estratégias organizacionais, processos e comportamentos.

Já no caso do sistema e estabelecimentos prisionais, os resultados apresentados abrem perspetivas e suscitam outras investigações que nos permitam efetuar uma análise profunda do sistema tendo em vista a sua melhoria com o objetivo de providenciar as condições necessárias a fim de evitar a reincidência criminal. Neste sentido, e de modo a alcançar a adaptação, educação e humanização do Sistema Prisional que tanto almejamos, consideramos que seria importante desenvolver estudos que (re)analisassem a ação profissional dos Dirigentes dos EP's e das Chefias do Corpo da Guarda Prisional; as necessidades formativas do Corpo da Guarda Prisional; especializações na missão do Corpo da Guarda Prisional; o Circuito de Informação na DGRSP; as vantagens a nível de organização hierárquica com a criação de um Comando Único para o Corpo da Guarda Prisional; e a dimensão social da profissão de Guarda Prisional do ponto de vista da própria sociedade.

Os valores são o núcleo do que as pessoas são. Estes influenciam as suas escolhas, em quem confiam, a quem respondem e o modo como investem o seu tempo e energia. Os valores são um elemento crítico da cultura organizacional, tendo impacto tanto no desempenho individual como organizacional (Schein, 2010). Hoje em dia, os valores começam a assumir uma importância cada vez maior nas organizações, uma vez que os valores partilhados surgem como uma vantagem competitiva (Isenhardt et al., 2019). Os novos trabalhadores da geração atual já não se juntam "às cegas" a uma organização. Tal é particularmente evidente nos relatos dos participantes mais jovens, que além de um salário, procuram uma sensação de significado no seu trabalho. Esperam sentir-se confortáveis com os valores da sua organização. Querem uma sensação de vinculação psicológica e se não a encontrarem são capazes de procurar noutro sítio (Ramos \& Jordão, 2013). No entanto, será que isto se aplica à conjuntura atual das prisões? Não estarão os jovens a juntar-se a uma organização precisamente porque precisam de emprego e de uma componente monetária para sobreviver, esquecendo a parte da congruência entre valores? Muitos dos guardas prisionais, especialmente os que detinham o grau académico de licenciado, explicitaram que ingressaram nesta profissão porque não conseguiram encontrar emprego na sua área de formação. Se tal se verificar, uma eventual incongruência de valores irá trazer consequências negativas para o bem-estar do indivíduo, incluindo uma maior propensão para vivenciar stress ocupacional, tal como foi evidenciado neste e noutros estudos. Esta investigação permite, então, alertar para a importância de os estabelecimentos prisionais terem guardas cujos valores vão ao encontro dos valores organizacionais, já que, para além de esta congruência ter vantagens competitivas, está também associada a uma menor perceção de stress ocupacional - o qual, como se sabe, também tem custos para a organização e para a sociedade.

Assim, os resultados deste estudo destacam a importância desta congruência de valores, nos processos de recrutamento, seleção e integração, uma vez que o processo de seleção permite às organizações localizar pessoas que compartilham dos seus valores e o processo de integração constitui uma forma de moldar os valores individuais, alinhá-los com os valores organizacionais e diminuir possíveis conflitos derivados das diferentes perceções da realidade da organização (Roseira, 2017). Neste sentido, os processos de socialização anteriormente referidos assumem particular importância em indivíduos que irão assumir posições de chefias, pois só assim é possível garantir que os indivíduos de níveis hierarquicamente superiores abandonem, definitivamente, o "modelo do guarda prisional carcereiro" (Pereira, 2011, p. 38) e defendam o potencial ressocializador da prisão. Uma vez que a progressão na carreira de guarda prisional ocorre através da antiguidade na categoria (Santos, 2010), torna-se, assim, necessário repensar todo este processo de progressão, de modo a garantir que os indivíduos que chegam à categoria de chefe compartilham dos valores explícitos do seu estabelecimento prisional.

Por outro lado, o guarda tem um desenvolvimento pessoal próprio que deve ser compatível com o restante grupo profissional, mas será espectável que um conjunto de pessoas atuem da mesma forma, apenas porque receberam a mesma formação? Assistimos a uma nova dimensão: um profissional que foi formado, sabe o seu papel dentro do sistema prisional, mas age com base na sua identidade e, simultaneamente, constrói-se um ser solitário que muitas vezes é posto de lado pelo seu grupo profissional 
"por remar contra a maré" (P03) ou "ir contra os valores arcaicos do sistema" (P06). Isto tem um impacto tremendo quer no seu bem-estar, como, inevitavelmente, no próprio funcionamento do sistema prisional. Só assim, podemos almejar a humanização do sistema prisional português, que continua a ser, ano após ano, um fator preocupante para o Comité da ONU contra a Tortura e Outros Tratamentos ou Penas Cruéis, Desumanos ou Degradantes (Costa et al.,2017).

Esta é uma profissão de sentidos que influenciam na tomada de decisão dentro de uma mescla de tarefas a que o exercício da função o obriga. A panóplia de tarefas de um guarda prisional revela a importância de uma aprendizagem diversificada, evidencia a importância do saber escolher, do saber gerir estratégias, que perante situações idênticas culminem numa tomada de decisão de forma idêntica entre o grupo de guardas prisionais. Todavia, parece não haver preocupação da parte das entidades responsáveis no estudo e na possível mudança que poderá ser requerida nos seus corpos de intervenção. Sendo o guarda prisional o elemento mais próximo do recluso, é de extrema importância analisar as suas atitudes e os seus comportamentos, avaliando a sua componente relacional, concluindo se vai de encontro - ou não -, do que prima nos objetivos do sistema prisional e do seu código de execução de penal e medidas privativas da liberdade. Caso tal não aconteça, o carácter ressocializador das prisões não passará, para já, de uma utopia. Uma vez que a "satisfação no trabalho", apontada como um dos maiores fatores preditivos de stress nesta profissão, é uma atitude que resulta da avaliação que periodicamente cada trabalhador faz relativamente ao grau de realização dos seus valores, necessidades, preferências e expetativas profissionais (Costa et al., 2017), dando seguimento a esta linha de investigação estar-se-á a contribuir para que a Psicologia Organizacional continue a fazer jus ao desafio a que se propõe - "a busca do trabalhador feliz/produtivo -, um objetivo que pode ser alcançado se incrementarmos fortemente o nosso conhecimento acerca das atitudes, comportamentos e valores dos trabalhadores" (Arruda, 2013, p. 50).

\section{REFERÊNCIAS}

Arruda, P. F. M. (2013). Stress, burnout e estratégias de coping nos guardas prisionais da Região Autónoma dos Açores [Dissertação de Mestrado não publicada]. Universidade dos Açores.

Afonso, J., \& Gomes, R. (2009) Stress Ocupacional em Profissionais de Segurança Pública - Um estudo com militares da GNR. Psicologia: Reflexão e Crítica, 22(2), 294-303. https://doi.org/10.1590/S010279722009000200017.

Bardin, L. (2011). Análise de conteúdo. Edições 70, Lda.

Bloor, M. \& Wood, F. (2006). Keywords in Qualitative Research: A Vocabulary of Research Concepts. Sage.

Butler,D., Tasca, M., Zhang, Y. \& Carpenter, C. (2019). A systematic and meta-analytic review of the literature on correctional officers: Identifying new avenues for research. Journal of Criminal Justice, 60(1), 8492. https://doi.org/10.1016/j.jcrimjus.2018.12.002

Cardoso, C. (2014). Guardas Prisionais "Presos" ao Burnout: Estudo Comparativo entre EP.s de Alta e Média Segurança, com Elevado e Médio Grau de Complexidade de Gestão [Dissertação de Mestrado não publicada]. Universidade Lusófona do Porto.

Coelho, C. (2008). Atitudes de Guardas Prisionais Relativamente a Contactos Sexuais Entre Reclusos e à Sua Prevenção [Dissertação Mestrado não publicada]. Universidade do Minho.

Cooper, C. L., \& Marshall, J. (1976). Occupational sources of stress: A review of the literature relating to coronary heart disease and mental ill health. Journal of Occupational Psychology, 49(1), 11-28. https://doi.org/10.1111/j.2044-8325.1976.tb00325.x

Costa, V., Monteiro, S., Esgalhado, \& Pereira, H. (2017). Investigação psicológica em contexto prisional português: Uma revisão sistemática da literatura e desafios futuros para a investigação. Psicologia, 31(1), 49-58. http://dx.doi.org/10.17575/rpsicol.v31i1.1238.

Cunha, I. (1996). O corpo recluído: controlo e resistência numa prisão feminina. Celta Editora.

Direção Geral da Reinserção e dos Serviços Prisionais (2020). Portal da Direção Geral da Reinserção e dos Serviços Prisionais. Acedido a abril, 9 de 2020 em https://dgrsp.justica.gov.pt/

Edwards, J. R., \& Cable, D. A. (2009). The value of value congruence. Journal of Applied Psychology, 94(3), 654-677. https://doi.org/10.1037/a0014891

Festinger L. (1957). A theory of cognitive dissonance. Row \& Peterson.

French, J. R., Caplan, R. D., \& Harrison, R. V. (1982). The mechanisms of job stress and strain. Wiley.

Gonçalo, H., Gomes R. Barbosa, F., \& Afonso J. (2010). Stresse ocupacional em forças de segurança: Um estudo comparativo (versão electrónica). Análise Psicológica, 28, 165-178. https://doi.org/10.1590/S0104-12902013000300005

Gonçalves, R. A. \& Vieira, S. (2005). Atitudes face aos reclusos em guardas prisionais: implicações para a formação do pessoal penitenciário. Temas Penitenciários, 3(1), 23-28. 
Isenhardt, A., Hostettler, U., \& Ramseier, E. (2019). Effects of Social Relations at Work and Support From Family and Friends on the Consequences of Inmate Violence on Correctional Staff Burnout. Criminal Justice and Behaviour, 46(10), 1-22. https://doi.org/10.1177/0093854819846529

Lambert, E., Keena,Haynes, S., May, D., Ricciardelli, R., \& Leone, M. (2019). Testing a path model of organizational justice and correctional staff job stress among southern correctional staff. Criminal Justice and Behaviour, 46(10), 1-18. https://doi.org/10.1177/0093854819843336

Lazarus, R. S., \& Folkman, S. (1984). Stress, appraisal, and coping. Springer.

Liedtka, J. M. (1989). Value congruence: The interplay of individual and organizational value systems. Journal of Business Ethics, 8(10), 805-815. https://doi.org/10.1007/bf00383780

Miles, M. B., \& Huberman, A. M. (1994). Qualitative data analysis.SAGE Publications, Inc.

Moreira, C. D. F. (2016). Guarda prisional: Força de segurança ou agente de ressocialização [Dissertação de Mestrado não publicada]. Universidade Nova de Lisboa.

Patton, M. Q. (2015). Qualitative research and evaluation methods. Integrating theory and practice (4th Ed.). Sage.

Pereira, J. (2011). Ser guarda prisional o informal na formação das identidades profissionais dos guardas prisionais [Dissertação de Mestrado não publicada]. Universidade do Porto.

Ramos, V., \& Jordão, F. (2013). Are public workers more stressed than private workers? The relationship between work stress and value congruence. Psychology Research, 3(7), 396-408. https://doi.org/10.17265/2159-5542/2013.07.005

Roseira, A.P. (2017). O estigma na vida pessoal do guarda prisional. Configurações Revista de Sociologia, 20, 93-108. https://doi.org/10.4000/configuracoes.4228

Sampieri, R. H., Collado, C. F., \& Lucio, P. B. (2014). Metodología de la Investigación (6ª Ed.). McGrawHill/Interamericana Editores, S. A. de C. V.

Santos, M.H. (2010); Agente penitenciário: trabalho no cárcere [Dissertação de Mestrado não publicada]. Universidade Federal do Rio Grande do Norte.

Schein, E. H. (2010). Organizational Culture and Leadership (4th Ed.). Jossey-Bass A Wiley Imprint.

Schiff, M. \& Leip, L. (2019). The impact of job expectations, workload, and autonomy on work- related stress among prison wardens in the United States. Criminal Justice and Behaviour, 46(1), 136-153. https://doi.org/ 10.1177/0093854818802876

Tetlock, P. E., Peterson, R. S., \& Lerner, J. S. (1996). Revising the value pluralism model: Incorporating social content and context postulates. In C. Seligman, J. Olson, \& M. Zanna (Eds.), The Psychology of Values: The Ontario Symposium (Vol.8, pp.25-51). Erlbaum.

Trounson, J., Pfeifer, E., \& Skues, J. L. (2019). Perceived workplace adversity and correctional officer psychological well-being: an international examination of the impact of officer response styles. The $\begin{array}{lllll}\text { Journal of Forensic Psychiatry \& Psychology, } & 30(1), & 17-37 .\end{array}$ https://doi.org/10.1080/14789949.2018.1441427

Yin, R. K. (2011). Applications of case study research. London: SAGE Publications, Inc.

Zhang, T., Gino, F., \& Margolis, J. (2018). Does 'Could' Lead to Good? On the Road to Moral Insight. Academy of Management Journal, 61(3), 857-895. https://doi.org/10.5465/amj.2014.0839

$\begin{array}{lr}\text { Historial do artigo } \\ \text { Recebido } & 03 / 2019 \\ \text { Aceite } & 07 / 2020 \\ \text { Publicado } & 12 / 2020\end{array}$




\section{Apêndice}

Sistema de categorias

Free Nodes \begin{tabular}{ll}
\hline Verbalizações da & Nesta categoria estão incluídas todas as unidades de registo que se referem às verbalizações \\
Entrevistadora & da investigadora: perguntas, aprofundamentos e reformulações.
\end{tabular}

Verbalizações do Entrevistado
Nesta categoria estão incluídas todas as unidades de registo que se referem às verbalizações do entrevistado que não estão diretamente relacionadas com os objetivos do estudo.

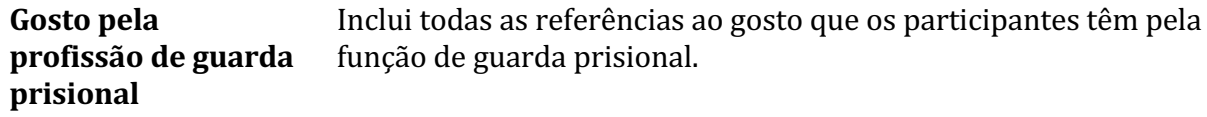

Outras fontes de Inclui todas as referências a dimensões organizacionais, que não se stress ocupacional relacionam com os valores, consideradas pelos participantes como fontes de stress ocupacional no exercício da função de guarda prisional.

Efeitos do stress Inclui todas as verbalizações dos entrevistados acerca dos efeitos que o stress associado ao exercício da profissão tem na sua vida pessoal e profissional.

\section{Considerações do entrevistado acerca da temática dos valores e/ou da importância do estudo}

\section{Considerações do entrevistado acerca dos reclusos/visitas}

Barreiras à
ressocialização
e/ou
vigilância/punição

Expectativas de papel
Inclui todas as verbalizações em que o entrevistado expressa as suas considerações pessoais acerca da temática dos valores e/ou da importância do presente estudo.
Outros

Inclui todas as verbalizações do entrevistado acerca dos reclusos e das visitas que recebem (por ex., relação guarda-recluso, características da população reclusa, relação com as visitas e familiares do recluso, ...).

Inclui todas as verbalizações do entrevistado sobre as barreiras (sociais, políticas, culturais, ...) que dificultam o sucesso do processo de ressocialização e/ou de vigilância/punição dos reclusos.

Inclui todas as verbalizações do entrevistado acerca das expectativas que tinha sobre o papel do guarda prisional no início da sua carreira.

Inclui todas as verbalizações do entrevistado que não se integram nas categorias e subcategorias definidas. 


\section{Tree Nodes}

\begin{tabular}{ll}
\hline Reconhecimento & Nesta categoria estão incluídas todas as unidades de registo em que o participante faz o \\
dos valores & reconhecimento dos valores (Punir/Vigiar e Ressocializar), pessoais e organizacionais, \\
& implícitos e explícitos.
\end{tabular}

\section{Reconhecimento dos valores pessoais}

\section{Reconhecimento dos valores organizacionais}

Nesta categoria integram-se todas as unidades de registo em que os guardas prisionais identificam os seus valores pessoais.

Nesta categoria inserem-se todas as unidades de registo em que os guardas prisionais identificam os valores organizacionais, implícitos e explícitos.

\section{Reconhecimento dos valores do sistema prisional

Reconhecimento
dos valores do
estabelecimento
prisional

Nesta categoria integram-se todas as unidades de registo em que os guardas prisionais identificam os valores do sistema prisional português.

\begin{abstract}
Nesta categoria integram-se todas as unidades de registo em que os guardas prisionais identificam os valores, implícitos e explícitos, do seu estabelecimento prisional.
\end{abstract}

Valores Nesta categoria integram-se Implícitos todas as unidades de registo em que os guardas prisionais identificam os valores organizacionais implícitos, veiculados pelos grupos informais da organização, que definem os reais objetivos da organização e dos seus membros.

Valores Nesta categoria inserem-se Explícitos todas as unidades de registo em que os guardas prisionais identificam os valores organizacionais visíveis, definidos e explicitados na missão da organização.

\section{Congruência de valores}

Nesta categoria estão incluídas todas as unidades de registo que se referem à perceção de congruência, entre os valores pessoais dos guardas prisionais e os valores, implícitos e/ou explícitos, da sua organização.

P-O fit subjetivo Nesta categoria estão incluídas todas as unidades de registo que se referem à perceção de ajustamento (fit) ou de desajustamento (misfit) entre os valores pessoais dos guardas prisionais e os valores, implícitos e/ou explícitos, da sua organização.

Codificam-se, nesta categoria, todas as unidades de registo que se referem ao ajustamento percecionado pelos guardas prisionais, entre os seus valores pessoais e os valores, implícitos e/ou explícitos, da sua organização.
Codificam-se, nesta categoria, todas as unidades de registo que se referem ao desajustamento percecionado pelos guardas prisionais, entre os seus valores pessoais e os valores, implícitos e/ou explícitos, da sua organização. 
Conflito de Valores percecionado

Nesta categoria estão incluídas todas as unidades de registo que se referem ao conflito percecionado pelos guardas prisionais entre os seus valores pessoais (punir/vigiar e ressocializar) e os valores da sua organização ou entre o grau de punição/vigilância e ressocialização que defendem e o grau aplicado pela sua organização.

\section{Conflito \\ Punir/Vigiar e \\ Ressocializar}

\section{Conflito no grau \\ de Punição/ \\ Vigilância e \\ Ressocialização}

Codificam-se, nesta categoria, todas as unidades de registo que se referem ao conflito percecionado pelos guardas prisionais entre os seus valores pessoais (punir/vigiar e ressocializar) e os valores da sua organização.

Codificam-se nesta categoria todas as unidades de registo que se referem ao conflito percecionado pelos guardas prisionais, entre o grau de punição/vigilância e ressocialização que defendem, e o grau aplicado pela sua organização.

\section{Papel da \\ Congruência de Valores no Stress Ocupacional}

\begin{abstract}
Nesta categoria estão incluídas todas as unidades de registo que se referem ao papel da congruência de valores (P-O fit e Conflito) na vivência do stress ocupacional percecionados pelos guardas prisionais.
\end{abstract}

\section{Papel do P-O fit na vivência do Stress Ocupacional}

Nesta categoria estão incluídas todas as unidades de registo que se referem ao papel do $P$-O fit subjetivo na vivência do stress ocupacional percecionado pelos guardas prisionais.
Codificam-se, nesta categoria, todas as unidades de registo que se referem ao papel do ajustamento subjetivo, entre os valores pessoais e os valores organizacionais, implícitos e/ ou explícitos, na vivência do stress ocupacional, percecionados pelos guardas prisionais.

Misfit Codificam-se, nesta categoria, todas as unidades de registo que se referem ao papel do desajustamento subjetivo, entre os valores pessoais e os valores organizacionais, implícitos e/ou explícitos, na vivência do stress ocupacional, percecionados pelos guardas prisionais.

Papel do Conflito de Valores na Vivência do Stress Ocupacional
Nesta categoria estão incluídas todas as unidades de registo que se referem ao papel do conflito de valores ou do grau de Punição/ Vigilância e Ressocialização aplicados, na vivência do stress ocupacional percecionado pelos guardas prisionais.

\section{Conflito \\ Punir/Vigiar e \\ Ressocializar}

Codificam-se, nesta categoria, todas as unidades de registo que se referem ao papel do conflito entre os valores pessoais (punir/vigiar e ressocializar) e os valores organizacionais, na vivência de stress ocupacional pelos guardas prisionais.

Conflito no grau Codificam-se, nesta categoria, todas as de Punição/ Vigilância e Ressocialização unidades de registo que se referem ao papel do conflito entre o grau de punição/vigilância e de ressocialização pessoal e o grau aplicado pela organização, tem na vivência de stress ocupacional pelos guardas prisionais. 
Congruência de valores e stress ocupacional em guardas prisionais 